\title{
Programmable Oligomers for Minor Groove DNA Recognition
}

\author{
Raymond M. Doss, Michael M. Marques, Shane Foister, \\ David M. Chenoweth, and Peter B. Dervan* \\ The Division of Chemistry and Chemical Engineering \\ California Institute of Technology, Pasadena, CA 91125, USA. \\ Email: dervan@caltech.edu
}

\section{Supporting Information:}

General. $N, N$-dimethylformamide (DMF), $N, N$-diisopropylethylamine (DIEA), thiophenol (PhSH), 3dimethylamino-1-propylamine (Dp), Triethylamine (TEA), and thiourea were purchased from Aldrich. Boc- $\beta$-alanine-(4-carbonylaminomethyl)benzyl-ester-copoly(styrenedivinylbenzene) resin (Boc- $\beta$-Pamresin), dicyclohexylcarbodiimide (DCC), hydroxybenzotriazole (HOBt), 2-(1H-benzotriazol-1-yl)1,1,3,3-tetramethyluronium hexafluorophosphate (HBTU), 4-dimethylaminopyridine (DMAP), and Boc- $\beta$-alanine were purchased from NOVA Biochem. Trifluoroacetic acid (TFA) was purchased from Halocarbon. All other solvents were reagent grade from EMD Chemicals. Oligonucleotide inserts were synthesized by the Biopolymer Synthesis Center at the California Institute of Technology. Precoated silica gel plates $60 \mathrm{~F}_{254}$ for TLC and silica gel $60(40 \mu \mathrm{m})$ for flash chromatography were from Merck. Glycogen $(20 \mathrm{mg} / \mathrm{mL})$, dNTPs (PCR nucleotide mix), and all enzymes, unless otherwise stated, were purchased from Boehringer-Mannheim. pUC19 was purchased from New England Biolabs, and deoxyadenosine $\left[\gamma^{32} \mathrm{P}\right]$ triphosphate was provided by ICN. Calf thymus DNA (sonicated, deproteinized) and DNaseI (7500 units/mL, FPLC pure) were from Amersham Pharmacia. AmpliTaq DNA polymerase was from Perkin-Elmer and used with the provided buffers. Tris.HCl, DTT, RNase-free water, and 0.5 M EDTA were from United States Biochemical. Calcium chloride, potassium chloride, and magnesium chloride were purchased from Fluka. Tris-borate-EDTA was from GIBCO, and bromophenol blue was from Acros. All reagents were used without further purification. NMR spectra were recorded on a Varian spectrometer at $300 \mathrm{MHz}$ in DMSO- $d_{6}$ or $\mathrm{CDCl}_{3}$, with chemical shifts reported in parts per million relative to residual solvent. UV spectra were measured on a Hewlett-Packard model 8452A diode-array spectrophotometer. High-resolution FAB and EI mass spectra were recorded at the Mass Spectroscopy Laboratory at the California Institute of Technology. Matrix-assisted laser desorption/ionization time-of-flight mass spectrometry (MALDI-TOF-MS) was conducted at the Mass Spectroscopy Laboratory at the California Institute of Technology.

Heterocycle Synthesis. The synthesis of compounds 4 (Boc-Py-OBt), 5 (Boc-Im-OH), 10 (Boc-Py-Bi$\mathrm{OH}), 11$ (Boc-Im-HzOMe-OH), 19 (Ct-OH), 10, 22 (Im-HzOMe-OH), and 16 (aryl diamine) have previously been reported. ${ }^{1,2}$

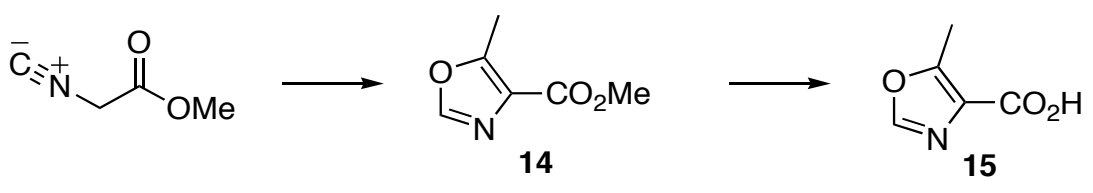

Methyl 5-methyl-1,3-oxazole-4-carboxylate (No-OMe) 14: (Compound 14 was prepared following an exact preparation reported by Suzuki et al. ${ }^{3}$ and purified by normal phase column chromatography.) 
According to the Suzuki procedure a mixture of methyl-alpha-isocyanoacetate $(3.0 \mathrm{~g}, 30.2 \mathrm{mmol})$ and DBU $(4.5 \mathrm{~g}, 30.2 \mathrm{mmol})$ in dry THF $(40 \mathrm{~mL})$ at $10^{\circ} \mathrm{C}$, was treated with acetic anhydride $(3.06 \mathrm{~g}, 30$ $\mathrm{mmol})$ in dry THF $(10 \mathrm{~mL})$ dropwise. The reaction was allowed to warm to room temperature and stirred for $10 \mathrm{~h}$. The solvent was removed by rotoevaporation and water $(100 \mathrm{~mL})$ was added. The mixture was extracted with EtOAc $(2 \times 100 \mathrm{~mL})$. The organic layers were combined, dried over sodium sulfate, filtered, and concentrated in vacuo to provided 14 as a crude amber oil. The oil was subjected to column chromatography using (3:2 Hex/EtOAc) to provide $14(2.73 \mathrm{~g}, 64 \%$ Yield) as a crystalline white solid. TLC (3:2 Hex/EtOAc) $R_{f} 0.5 ;{ }^{1} \mathrm{H}$ NMR (DMSO- $\left.d_{6}\right) 8.32(\mathrm{~s}, 1 \mathrm{H}), 3.77(\mathrm{~s}, 3 \mathrm{H}), 2.55(\mathrm{~s}, 3 \mathrm{H}) ;{ }^{13} \mathrm{C}$ $\left(\mathrm{DMSO}-d_{6}\right)$ 161.9, 156.1, 150.3, 126.2, 51.5, 11.5; HR-MS (EI): calcd for $\mathrm{C}_{6} \mathrm{H}_{7} \mathrm{NO}_{3}$ : 141.0426; found: 141.0427.

5-Methyl-1,3-oxazole-4-carboxylic acid (No-OH) 15: A mixture of 14 (1 g, $7.08 \mathrm{mmol}), 1 \mathrm{~N} \mathrm{NaOH}$ $(10 \mathrm{~mL})$ and $\mathrm{MeOH}(5 \mathrm{~mL})$ was stirred at $40{ }^{\circ} \mathrm{C}$ for $4 \mathrm{~h}$. The $\mathrm{MeOH}$ was removed by rotoevaporation and the $\mathrm{pH}$ adjusted to $\mathrm{pH}=2$ with $1 \mathrm{~N} \mathrm{HCl}$. The precipitate was extracted with EtOAc $(3 \times 10 \mathrm{~mL})$, the organics dried over sodium sulfate and removed by rotoevaporation to provide $\mathbf{1 5}$ (738 $\mathrm{mg}, 82 \%$ Yield) as a fibrous white solid. TLC $(3: 2 \mathrm{EtOAc} / \mathrm{Hex}+10 \% \mathrm{AcOH}) R_{f} 0.4 ;{ }^{1} \mathrm{H} \mathrm{NMR}\left(\mathrm{DMSO}-d_{6}\right) 8.27(\mathrm{~s}, 1 \mathrm{H})$, $2.45(\mathrm{~s}, 3 \mathrm{H}) ;{ }^{13} \mathrm{C}\left(\mathrm{DMSO}-d_{6}\right)$ 163.0, 155.6, 150.1, 145.6, 11.6; HR-MS (EI): calcd for $\mathrm{C}_{5} \mathrm{H}_{5} \mathrm{NO}_{3}$ : 127.0269; found: 127.0268 .

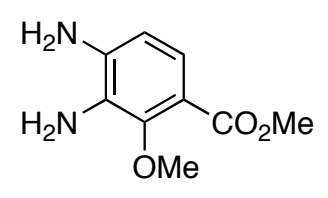

16

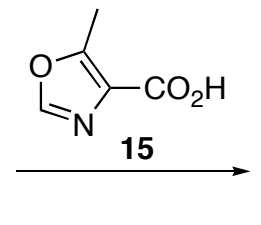

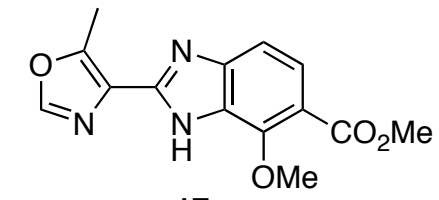

17

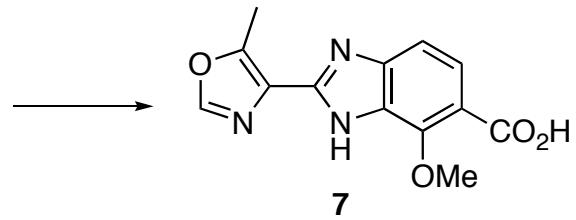

7

Methyl 7-methoxy-2-(5-methyl(1,3-oxazole-4-yl))benzimidazole-6-carboxylate (NoHz(OMe)OMe) 17: To a solution of $\mathbf{1 5}(0.3 \mathrm{~g}, 2.36 \mathrm{mmol})$ in DMF (4 mL) was added DIEA (915 mg, $1.23 \mathrm{~mL}, 7.08$ mmol) and HBTU (895 mg, $2.36 \mathrm{mmol}$ ). The mixture was stirred at room temperature for $1 \mathrm{~h}$, followed by the addition of the aryl diamine $16(463 \mathrm{mg}, 2.36 \mathrm{mmol})$. The reaction was then heated to $35^{\circ} \mathrm{C}$ and stirred for an additional $24 \mathrm{~h}$. The reaction was allowed to cool to room temperature and then poured into a separatory funnel containing water $(200 \mathrm{~mL})$. The water was then extracted with EtOAc $(2 \times 100$ $\mathrm{mL}$ ). The organic layer was dried over anhydrous sodium sulfate and concentrated in vacuo to provide a crude solid, which was dissolved in glacial acetic acid $(5 \mathrm{~mL})$ and heated to $90{ }^{\circ} \mathrm{C}$. The reaction was stirred for $12 \mathrm{~h}$, followed by removal of the solvent by rotoevaporation. The resultant residue was subjected to column chromatography $(4: 1 \mathrm{EtOAc} / \mathrm{Hex})$ to provide $\mathbf{1 7}$ as a thin film. Addition of hexanes to the film, followed by rotoevaporation and drying under high vacuum provided $\mathbf{1 7}$ as a white solid (379 mg, 56\% Yield). TLC (4:1 EtOAc/Hex) $R_{f} 0.75 ;{ }^{1} \mathrm{H}$ NMR (DMSO- $\left.d_{6}\right) 8.49$ (s, $\left.1 \mathrm{H}\right), 7.51$ (d, $1 \mathrm{H}, J=8.7 \mathrm{~Hz}), 7.16(\mathrm{~d}, 1 \mathrm{H}, J=8.7 \mathrm{~Hz}), 4.34(\mathrm{~s}, 3 \mathrm{H}), 3.77(\mathrm{~s}, 3 \mathrm{H}) 2.78(\mathrm{~s}, 3 \mathrm{H}) ;{ }^{13} \mathrm{C}\left(\mathrm{DMSO}-d_{6}\right) 166.7$, 151.0, 149.3, 145.5, 139.0, 135.3, 125.6, 124.8, 114.2, 105.3, 60.8, 51.6, 11.3; HR-MS (EI): calcd for $\mathrm{C}_{14} \mathrm{H}_{13} \mathrm{~N}_{3} \mathrm{O}_{4}$ : 287.0906; found: 287.0914.

7-methoxy-2-(5-methyl(1,3-oxazole-4-yl))benzimidazole-6-carboxylic acid ( $\mathrm{NoHz}(\mathrm{OMe}) \mathrm{OH})$ 7: A mixture of $17(200 \mathrm{mg}, 0.69 \mathrm{mmol})$, DMSO $(0.8 \mathrm{~mL})$, and $1 \mathrm{~N} \mathrm{NaOH}(4 \mathrm{~mL})$ was stirred at $23{ }^{\circ} \mathrm{C}$ for 3 h. The solution was diluted with $8 \mathrm{~mL}$ of $\mathrm{H}_{2} \mathrm{O}$ and the $\mathrm{pH}$ was adjusted to $\mathrm{pH}=2$ with $1 \mathrm{~N} \mathrm{HCl}(4.4$ $\mathrm{mL})$. The precipitate was filtered and washed with diethyl ether. The crude material was purified by silica gel chromatography $(1: 1 \mathrm{EtOAc} / \mathrm{Hexanes}+2 \% \mathrm{AcOH}$ to $3: 1 \mathrm{EtOAc} / \mathrm{Hexanes}+2 \% \mathrm{AcOH})$ to provide 7 (156 mg, 82\% Yield) as a white solid after drying under high vacuum. TLC (3:1 EtOAc/Hex $+2 \% \mathrm{AcOH}) R_{f} 0.55 ;{ }^{1} \mathrm{H}$ NMR (DMSO- $\left.d_{6}\right) 13.12(\mathrm{~s}, 1 \mathrm{H}), 12.37(\mathrm{~s}, 1 \mathrm{H}), 8.51(\mathrm{~s}, 1 \mathrm{H}), 7.52(\mathrm{~d}, 1 \mathrm{H}, J=$ $8.5 \mathrm{~Hz}), 7.15(\mathrm{~d}, 1 \mathrm{H}, J=8.5 \mathrm{~Hz}), 4.34(\mathrm{~s}, 3 \mathrm{H}), 2.78(\mathrm{~s}, 3 \mathrm{H}) ;{ }^{13} \mathrm{C}\left(\mathrm{DMSO}-d_{6}\right) 167.8,151.1,150.9,149.3$, 
145.5, 139.0, 135.5, 125.8, 125.2, 115.2, 105.4, 60.9, 11.4; HR-MS (FAB): calcd for $\mathrm{C}_{13} \mathrm{H}_{12} \mathrm{~N}_{3} \mathrm{O}_{4}$ : 274.0828; found: $274.0833[M+\mathrm{H}]^{+}$.<smiles>COc1ccc(N)c(N)c1C(C)=O</smiles>

16

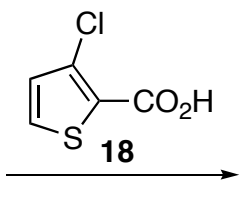

19

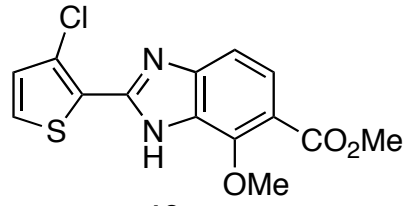

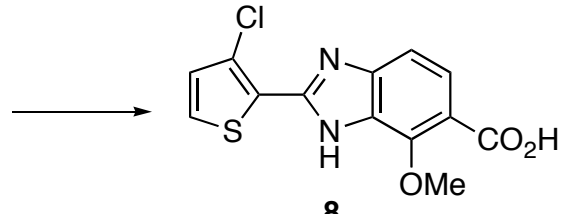

8

Ct-Hz(OMe)OMe 19: To a solution of 18 (294 mg, $1.80 \mathrm{mmol})$ in DMF (5 mL) was added DIEA $(0.348 \mathrm{~mL}, 1.98 \mathrm{mmol})$ and HBTU $(650 \mathrm{mg}, 1.72 \mathrm{mmol})$. The mixture was stirred at room temperature for $1 \mathrm{~h}$, followed by the addition of the aryl diamine $16(300 \mathrm{mg}, 1.80 \mathrm{mmol})$. The reaction was then heated to $35{ }^{\circ} \mathrm{C}$ and stirred for an additional $24 \mathrm{~h}$. The reaction was allowed to cool to room temperature and then poured into a Falcon tube containing cold water $(40 \mathrm{~mL})$ resulting in a cloudy precipitate. The Falcon tube was centrifuged at $14000 \mathrm{rpm}$ for $10 \mathrm{~min}$, the mother liquor decanted, and the precipitate dried under high vacuum. After drying, the crude solid was dissolved in glacial acetic acid (5 mL) and heated to $90{ }^{\circ} \mathrm{C}$. The reaction was stirred for $12 \mathrm{~h}$, followed by removal of the solvent by rotoevaporation. The resultant residue was subjected to column chromatography $(3: 2 \mathrm{EtOAc/Hex})$ to provide 19 as an off-white solid (647 mg, 57\% Yield). TLC (3:2 EtOAc/Hex) $R_{f} 0.5 ;{ }^{1} \mathrm{H}$ NMR (DMSO$\left.d_{6}\right) 12.85(\mathrm{~s}, 1 \mathrm{H}), 7.89(\mathrm{~d}, 1 \mathrm{H}, J=5.3 \mathrm{~Hz}), 7.56(\mathrm{~d}, 1 \mathrm{H}, J=8.5 \mathrm{~Hz}), 7.27(\mathrm{~d}, 1 \mathrm{H}, J=8.2), 7.26(\mathrm{~d}, 1 \mathrm{H}, J$ $=5.3), 4.30(\mathrm{~s}, 3 \mathrm{H}), 3.80(\mathrm{~s}, 3 \mathrm{H}) ;{ }^{13} \mathrm{C}\left(\mathrm{DMSO}_{6}\right) 166.6,151.2,144.0,139.8,134.8,129.7,129.4,126.3$, 125.6, 123.2, 114.8, 106.1, 61.2, 51.8; HR-MS (EI): calcd for $\mathrm{C}_{14} \mathrm{H}_{11} \mathrm{~N}_{2} \mathrm{O}_{3} \mathrm{SCl}$ : 322.0179; found: 322.0171.

(Ct-Hz(OMe)OH) 8: A mixture of 19 ( $1.8 \mathrm{~g}, 5.58 \mathrm{mmol}), 1 \mathrm{~N} \mathrm{NaOH}(36 \mathrm{~mL})$ and $\mathrm{MeOH}(27 \mathrm{~mL})$ was stirred at $45{ }^{\circ} \mathrm{C}$ for $24 \mathrm{~h}$. The $\mathrm{MeOH}$ was removed by rotoevaporation and the $\mathrm{pH}$ adjusted to $\mathrm{pH}=5.5$ with $1 \mathrm{~N} \mathrm{HCl}$, resulting in a precipitate. The mixture was spun down in a centrafuge ( 5 min at 14,000 $\mathrm{rpm}$ ). The tube was decanted leaving a white solid that was dried under high vacuum to provide 8 (2.6 g, Quant. Yield) as a light yellow solid. TLC $(3: 2 \mathrm{EtOAc} / \mathrm{Hex}+10 \% \mathrm{AcOH}) R_{f} 0.5 ;{ }^{1} \mathrm{H}$ NMR (DMSO$\left.d_{6}\right) 13.00(\mathrm{~s}, 1 \mathrm{H}), 7.89(\mathrm{~d}, 1 \mathrm{H}, J=5.3 \mathrm{~Hz}), 7.57(\mathrm{~d}, 1 \mathrm{H}, J=8.5 \mathrm{~Hz}), 7.30(\mathrm{~d}, 1 \mathrm{H}, J=8.5), 7.25(\mathrm{~d}, 1 \mathrm{H}, J$ $=5.3 \mathrm{~Hz}), 4.28(\mathrm{~s}, 3 \mathrm{H}) ;{ }^{13} \mathrm{C}\left(\mathrm{DMSO}-d_{6}\right) 167.7,151.1,143.9,139.7,134.9,129.6,129.3,126.4,125.7$, 123.2, 115.9, 106.1, 61.2; HR-MS (EI): calcd for $\mathrm{C}_{13} \mathrm{H}_{9} \mathrm{~N}_{2} \mathrm{O}_{3} \mathrm{SCl}$ : 308.0022; found: 308.0033 .

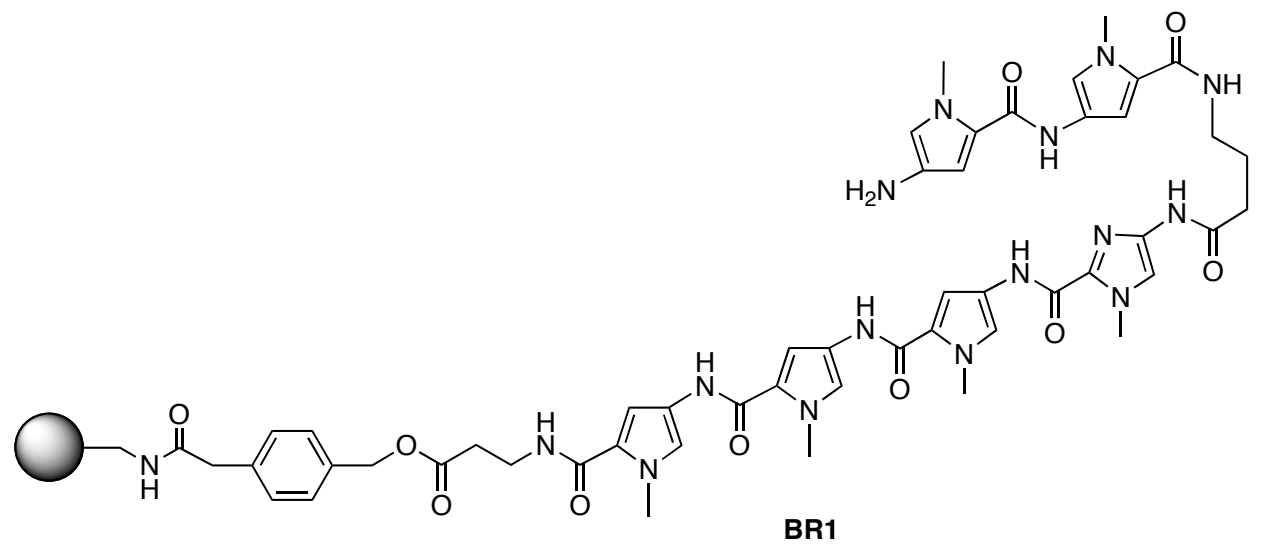

Polyamide Synthesis: Polyamides were synthesized from Boc- $\beta$-alanine-Pam resin (50 mg, 0.59 $\mathrm{mmol} / \mathrm{g}$ ) and purified by preparatory HPLC according to published manual solid phase protocols. ${ }^{4}$ The synthesis of batch resin BR1 $\left(\mathrm{H}_{2} \mathrm{~N}-\mathrm{Py}-\mathrm{Py}-\boldsymbol{\gamma}\right.$-Im-Py-Py-Py- $\beta$-Pam) has previously been reported. ${ }^{1}$ 

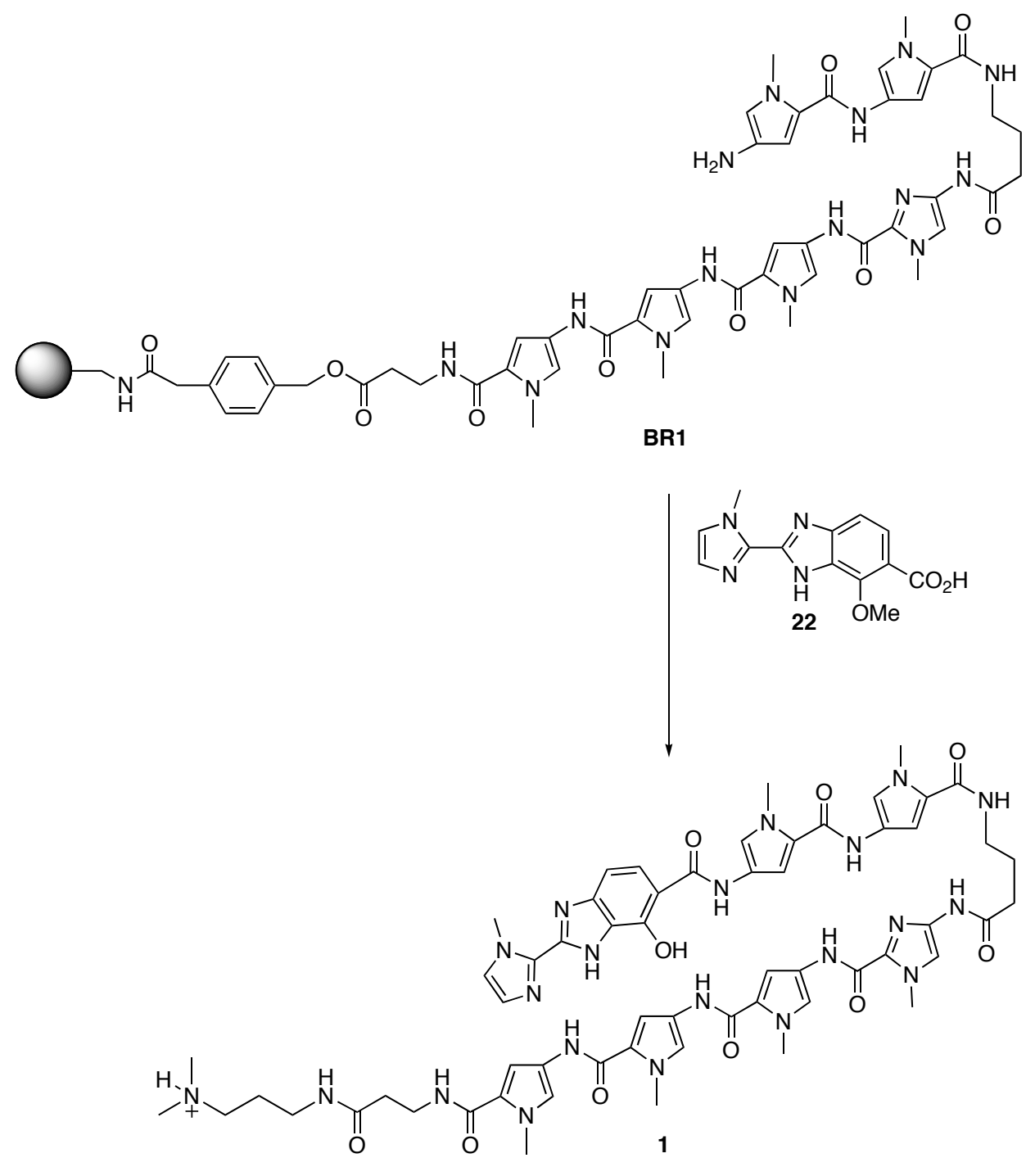

Im-Hz-Py-Py- $\gamma$-Im-Py-Py-Py- $\beta$-Dp (1): 22 (Im-HzOMe-OH) $(25$ mg, 88.5 umol) was incorporated by activation with HBTU (32 mg, $84 \mu \mathrm{mol})$, DIEA (23 mg, $31 \mu \mathrm{l}, 177 \mu \mathrm{mol})$ and DMF $(250 \mu \mathrm{l})$. The mixture was allowed to stand for $15 \mathrm{~min}$ at room temperature and then added to the reaction vessel containing base resin BR1 $\mathrm{H}_{2} \mathrm{~N}-\mathrm{Py}-\mathrm{Py}-\boldsymbol{\gamma}$-Im-Py-Py-Py- $\beta$-Pam. Coupling was allowed to proceed for 12 $\mathrm{h}$ at room temperature. The resin-bound polyamide was then washed with DCM and treated as described in the deprotection protocol below to provide Im-Hz-Py-Py- $\gamma$-Im-Py-Py-Py- $\beta$-Dp (1) $(0.9$ mg, $2.4 \%$ recovery) as a fine white powder under lyophilization of the appropriate fractions. MALDI-TOFMS: calcd for $\mathrm{C}_{59} \mathrm{H}_{70} \mathrm{~N}_{21} \mathrm{O}_{10}$ : 1232.56; found $1232.55[M+\mathrm{H}]^{+}$.

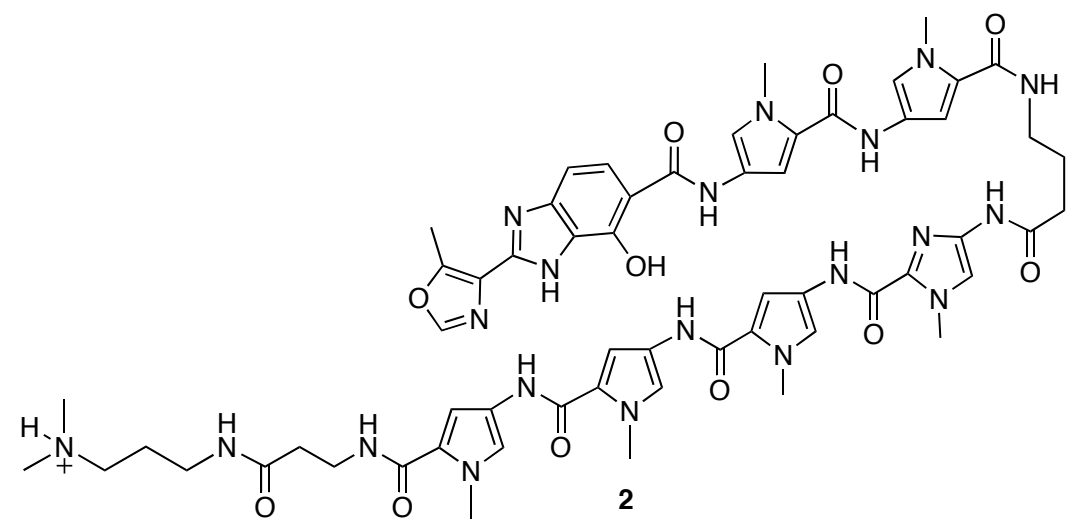


No-Hz-Py-Py- $\gamma$-Im-Py-Py-Py- $\beta$-Dp (2): 7 (No-HzOMe-OH) was incorporated as described above for Im-Hz-OH (polyamide 1) to provide No-Hz-Py-Py- $\gamma$-Im-Py-Py-Py- $\beta$-Dp (2) (1.5 mg, $4.1 \%$ recovery) as a fine white powder under lyophilization of the appropriate fractions. MALDI-TOF-MS: calcd for $\mathrm{C}_{59} \mathrm{H}_{69} \mathrm{~N}_{20} \mathrm{O}_{11}: 1233.55$; found $1233.54[M+\mathrm{H}]^{+}$.

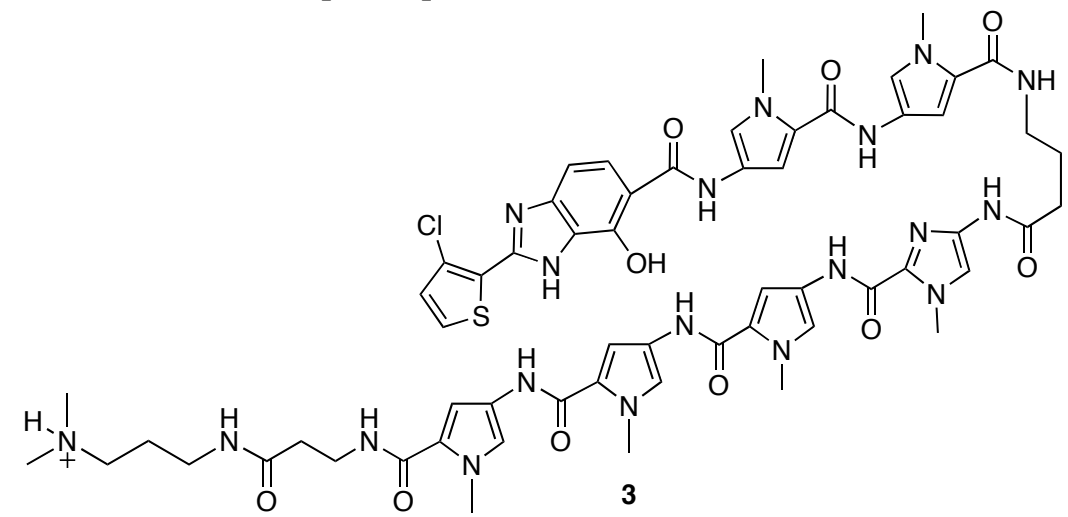

Ct-Hz-Py-Py- $\gamma$-Im-Py-Py-Py- $\beta$-Dp (3): $8(\mathbf{C t}-\mathbf{H z O M e - O H )}$ was incorporated as described above for Im-Hz-OH (polyamide 1) to provide Ct-Hz-Py-Py- $\gamma$-Im-Py-Py-Py- $\beta$-Dp (3) (1.1 mg, $2.9 \%$ recovery) as a fine white powder under lyophilization of the appropriate fractions. MALDI-TOF-MS: calcd for $\mathrm{C}_{59} \mathrm{H}_{67} \mathrm{ClN}_{19} \mathrm{O}_{10} \mathrm{~S}: 1269.47$; found $1269.47[M+\mathrm{H}]^{+}$.

Deprotection of the $\boldsymbol{O}$-Methyl-Protected Polyamides. $O$-Methyl protected polyamides were cleaved from resin, purified, deprotected and subject to further purification using the following general procedure. Upon completion of solid phase synthesis, 3-dimethylamino-1-propylamine (Dp) (500 $\mu \mathrm{L})$ was added to the synthesis vessel containing the resin $(50 \mathrm{mg})$. The mixture was allowed to stand for 2 $\mathrm{h}$ at $85{ }^{\circ} \mathrm{C}$ with occasional agitation. The resin was then filtered and the solution diluted to $8 \mathrm{~mL}$ using $0.1 \%$ TFA. The sample was purified by reversed phase HPLC and lyophilized to provide polyamides containing the $O$-methyl protected hydroxybenzimidazole unit (-HzOMe-) as a dry solid. The polyamides were then dissolved in DMF $(200 \mu \mathrm{l})$ and added to a suspension of sodium hydride (40 mg, $60 \%$ oil dispersion) and thiophenol $(200 \mu \mathrm{l})$ in DMF $(400 \mu \mathrm{l})$ that was pre-heated for $5 \mathrm{~min}$ at $85^{\circ} \mathrm{C}$. The mixture was heated for $2 \mathrm{~h}$ at $85{ }^{\circ} \mathrm{C}$. The mixture was then cooled to $0{ }^{\circ} \mathrm{C}$ and $20 \%$ TFA $(7.0 \mathrm{~mL})$ was added. The aqueous layer was washed three times with diethyl ether ( $8 \mathrm{~mL})$ and then diluted to a total volume of $9.5 \mathrm{~mL}$ using $0.1 \%$ TFA. The mixture was then purified by reverse-phase HPLC to give the deprotected $\mathbf{H z}$-containing polyamides 1, 2, and $\mathbf{3}$. 

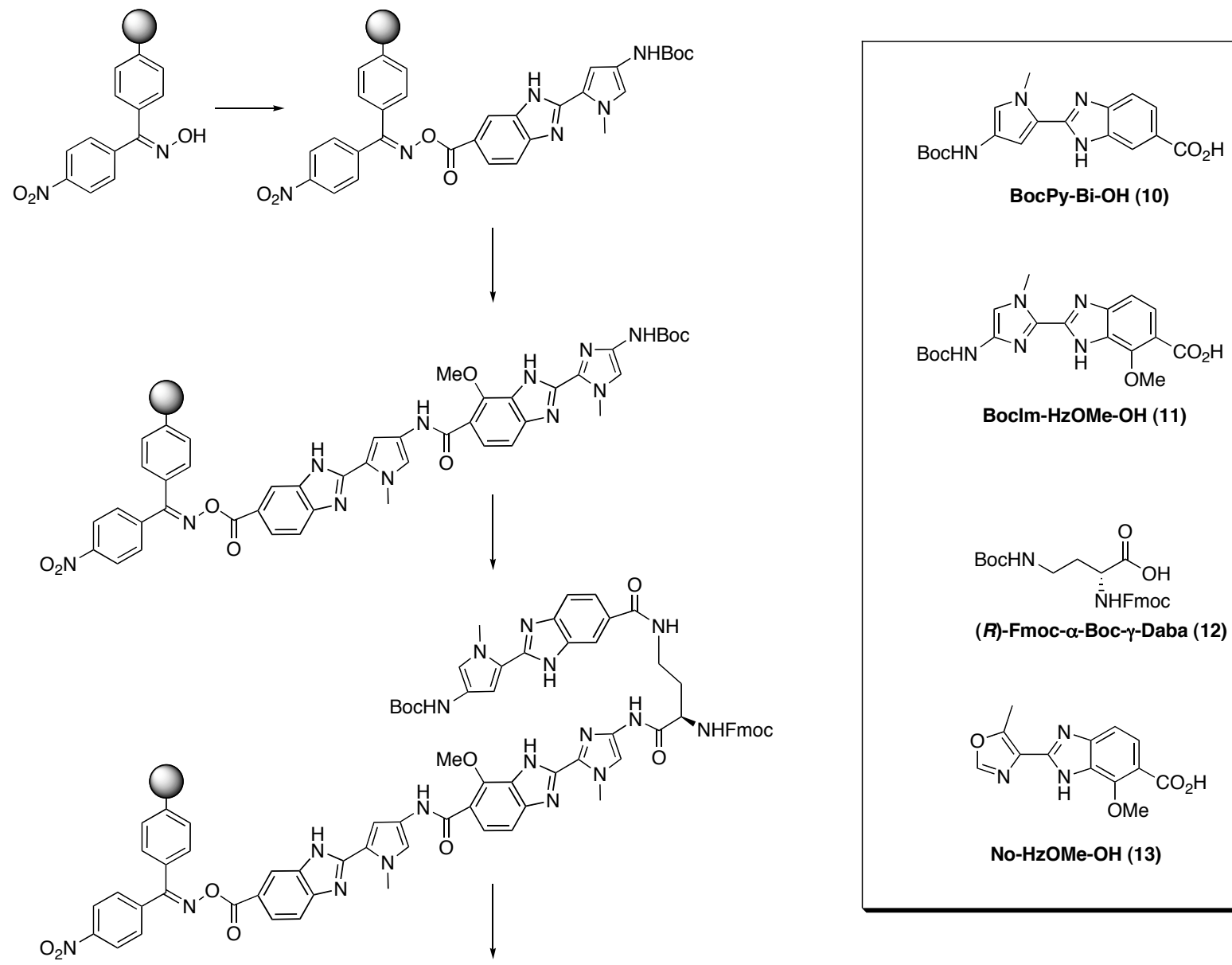

Boclm-HzOMe-OH (11)

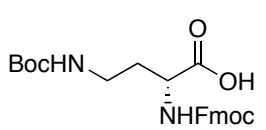

(R)-Fmoc- $\alpha$-Boc- $\gamma$-Daba (12)

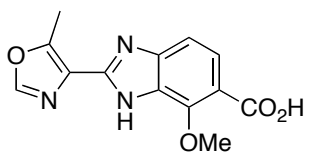

No-HzOMe-OH (13)
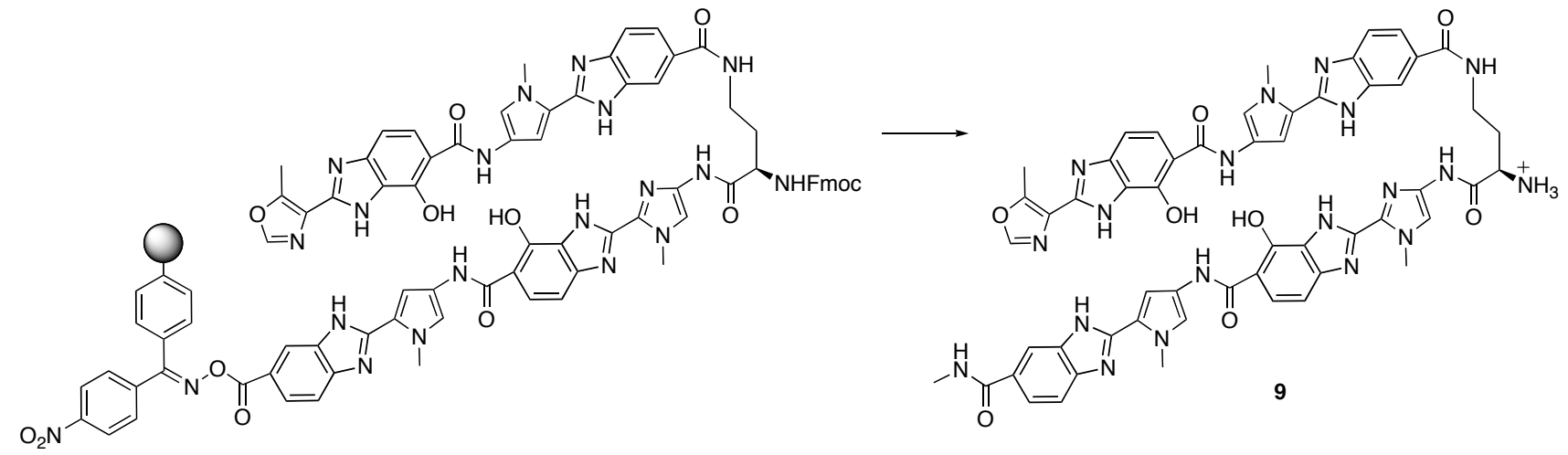

Oligomer 9 Synthesis. Oligomer 9 was prepared using Kaiser oxime resin ( 0.65 meqiv/gram) from Nova Biochem. Oxime resin (0.1 grams), was added to a solid phase synthesis vessel. The resin was then washed with DCM $(15 \mathrm{~mL})$ followed by DMF $(15 \mathrm{~mL})$. In a separate vessel was added Boc-PyBiOH (10) (60 mg, $0.168 \mathrm{mmol}$ ), HBTU (61 mg, $0.159 \mathrm{mmol}$ ), DIEA (43 mg, $60 \mu \mathrm{L}, 0.336 \mathrm{mmol}$ ), and DMF $(400 \mu \mathrm{L})$. The mixture was vortexed and allowed to activate for 20 minutes at room temperature. The activated mixture was then added to the resin. The reaction vessel was shaken at room temperature overnight. The reaction vessel was then drained and the resin washed with DMF $(15 \mathrm{~mL})$, followed by DCM $(15 \mathrm{~mL})$. The resin was then washed with a solution of $25 \%$ TFA in DCM $(20 \mathrm{~mL})$, followed by shaking with 25\% TFA in DCM at room temperature for 25 min to deprotect the Boc-protected alkyl amine, followed by shaking at room temperature for $25 \mathrm{~min}$ to deprotect the Boc-protected amine of pyrrole. In a separate vessel, a mixture of Boc-ImHz-OH (11) was activated using HBTU, DIEA, and $\mathrm{DMF}$ as described above. The reaction vessel containing the resin was then drained and washed with DCM $(15 \mathrm{~mL})$ and 10\% DIEA in DMF. The activated Boc-ImHz-OBt dimer was then added to the vessel containing (Resin-BiPy- $\mathrm{NH}_{2}$ ). The mixture was shaken at room temperature for 2.5 hours. The 
reaction vessel was then drained and washed with DMF (15 mL) and DCM (15 mL). A solution of 50\% TFA in DCM was then washed over the resin $(20 \mathrm{~mL})$, followed by shaking at room temperature for 25 minutes. In a separate vessel, a mixture of $\alpha$-Fmoc- $\gamma$-Boc- $(R)-2,4$-diaminobutyric acid $((R)$-Fmoc- $\alpha$ Boc- $\gamma$-Daba, 12) was activated using HBTU, DIEA, and DMF as described above. The reaction vessel containing the resin was then drained and washed with DCM $(15 \mathrm{~mL})$ and 10\% DIEA in DMF. The activated $(R)$-Fmoc- $\alpha$-Boc- $\gamma$-Daba-OBt monomer was then added to the vessel containing (Resin-BiPyHzIm- $\mathrm{NH}_{2}$ ). The mixture was shaken for 2 hours at room temperature. The reaction vessel was then drained and the resin washed with DMF $(15 \mathrm{~mL})$, followed by DCM $(15 \mathrm{~mL})$. The resin was then washed with a solution of $25 \%$ TFA in DCM $(20 \mathrm{~mL})$, followed by shaking with $25 \%$ TFA in DCM at room temperature for 25 min to deprotect the Boc-protected alkyl amine. In a separate vessel, a mixture of Boc-PyBi-OH (10) was activated using HBTU, DIEA and DMF as described above. The reaction vessel containing the resin was then drained and washed with DCM $(15 \mathrm{~mL})$ and 10\% DIEA in DMF. The activated Boc-PyBi-OBt dimer was then added to the vessel containing (Resin-BiPy-HzIm- $\gamma$ Daba$\mathrm{NH}_{2}$ ). The mixture was shaken at room temperature for 2.5 hours. The reaction vessel was then drained and the resin washed with DMF $(15 \mathrm{~mL})$, followed by DCM $(15 \mathrm{~mL})$. The resin was then washed with a solution of $25 \%$ TFA in DCM $(20 \mathrm{~mL})$, followed by shaking with $25 \%$ TFA in DCM at room temperature for $25 \mathrm{~min}$ to deprotect the Boc-protected alkyl amine, followed by shaking at room temperature with $25 \%$ TFA in DCM for 25 min to deprotect the Boc-protected amine of pyrrole. In a separate vessel, a mixture of $\mathrm{NoHzOMe}-\mathrm{OH}$ (13) was activated using HBTU, DIEA and DMF as described above for (10). The reaction vessel containing the resin was then drained and washed with DCM (15 mL) and 10\% DIEA in DMF. The activated NoHzOMe-OBt dimer was then added to the vessel containing (Resin-BiPy-HzIm- $\gamma$ Daba-BiPyNH$H_{2}$ ). The mixture was shaken at room temperature for 2.5 hours. The reaction vessel was then drained and washed with DMF $(15 \mathrm{~mL})$ and DCM $(15 \mathrm{~mL})$ to provide (Resin-BiPy-HzIm- $\gamma$ Daba-BiPy-HzNo).

O-Methyl Deprotection: To the synthesis vessel containing (Resin-BiPy-HzIm- $\gamma$ Daba-BiPy-HzNo) was added DCM $(800 \mu \mathrm{L})$ and $\mathrm{BCl}_{3}(400 \mu \mathrm{L})$, (2M in heptanes). The mixture was shaken at room temperature for 2.5 hours. The vessel was then drained and washed with DCM (15 mL). Deprotection was determined to be complete by analytical HPLC

Cleavage From Resin: Following O-Methyl deprotection, DCM $(200 \mu \mathrm{L})$ and $\mathrm{MeNH}_{2}(1 \mathrm{~mL})(2 \mathrm{M}$ in $\mathrm{THF}$ ) was added to the synthesis vessel. The mixture was then shaken at $35^{\circ} \mathrm{C}$ for $12 \mathrm{~h}$. The filtrate was collected from the synthesis vessel and the organics removed in vacuo. The remaining residue was dissolved in $0.1 \%$ TFA and purified using preparatory reverse phase HPLC. Lyophilization of the appropriate fractions provided oligomer 9 as a fine powder solid. MALDI-TOF-MS: calcd for $\mathrm{C}_{55} \mathrm{H}_{49} \mathrm{~N}_{19} \mathrm{O}_{8}$ : 1103.40; found $1103.41[M+\mathrm{H}]^{+}$.

\section{References}

1. Foister, S.; Marques, M. A.; Doss, R. M.; Dervan, P. B. Bioorg. Med. Chem. 2003, 11, 43334340.

2. Renneberg, D.; Dervan, P. B. J. Am. Chem. Soc. 2003, 125, 5707-5716.

3. Suzuki, M.; Iwasaki, T.; Miyoshi, M.; Okumura, K.; Matsumoto, K. J. Org. Chem. 1973, 38, 3571-3575.

4. Baird, E. E.; Dervan, P. B. J. Am. Chem. Soc. 1996, 118, 6141-6146. 